\title{
PEMANFAATAN SERAT KELAPA SEBAGAI REINFORCING FILLERS PADA PEMBUATAN KARET EBONIT
}

\author{
Utilization of Coconut Fiber as a Reinforcing Filler in the making of Ebonite Rubber \\ Hari Adi Prasetya ${ }^{1^{\star}}$, Popy Marlina ${ }^{1}$ \\ ${ }^{1}$ Balai Riset dan Standardisasi Industri Palembang, Jalan Perindustrian II, KM.9 No.12 Sukarami, \\ Palembang \\ *main contributor and corresponding author \\ e-mail: hariadiprasetya@yahoo.co.id
}

Diterima: 18 Februari 2020; Direvisi: 18 Juni 2020; Disetujui: 18 Juni 2020

\begin{abstract}
Abstrak
Pembuatan karet ebonit dari komposit karet alam dan serat kelapa telah dipelajari. Tujuan penelitian untuk menentukan karakteristik terbaik dari karet ebonit yang dibuat dengan komposit karet alam dengan serat kelapa. Sifat mekanik karet ebonit yang dihasilkan dibandingkan dengan karet ebonit dengan bahan pengisi carbon black. Proses vulkanisasi pada pembuatan karet ebonit, dilakukan menggunakan sulfur sebanyak 45 phr, sedangkan penggunaan serat kelapa bervariasi yaitu 15, 25, 35, 45 dan 55 phr. Parameter karet ebonit yang diamati meliputi, kekerasan, tegangan putus, perpanjangan putus, ketahanan sobek dan ketahanan ozon. Hasil penelitian menunjukkan bahwa kekerasan, tegangan putus dan ketahanan sobek untuk semua perlakuan meningkat dengan meningkatnya jumlah filler, sedangkan perpanjangan putus menunjukkan tren penurunan dengan meningkatnya jumlah filler. Karakteristik terbaik diperoleh pada perlakuan bahan pengisi serat kelapa (SK) 45 phr, dengan nilai kekerasan 82 Shore D, tegangan putus sebesar 6,8 MPa, perpanjangan putus dengan nilai $40 \%$ dan ketahanan sobek $60 \mathrm{~N} / \mathrm{mm}^{2}$ dan tidak ada retak (no crack) pada semua perlakuan setelah 48 jam pengamatan. Efek yang sama diperoleh karakteristik karet ebonit menggunakan bahan pengisi carbon black 45 phr, dengan karakterisitk mekanik yang memiliki nilai tidak signifikan dengan karet ebonit dengan pengisi serat kelapa. Karakteristik terbaik ebonit yang dihasilkan memenuhi persyaratan karet ebonit komersial.
\end{abstract}

Kata kunci: Karet ebonit, komposit karet alam, serat kelapa, sifat mekanik.

\begin{abstract}
The making of rubber ebonite from natural rubber composites and coconut fibers had been studied. The purpose of this study was to determine the best characteristics of rubber,'s ebonite that made with the natural rubber composites with coconut fibers. The mechanical properties of produced rubber ebonite were compared with rubber's ebonite with carbon black fillers. The process of vulcanization in making rubber ebonite was carried out using sulfur as much as 45 phr, while the use of recycled fiber varies, namely 15, 25, 35, 45 and 55 phr. Rubber ebonite parameters observed included hardness, tensile strength, elongation at break, tear resistance and ozone resistance. The results showed that the hardness, tensile strength and tear resistance for all treatments that increased with loading of fillers increasing, while elongation at break showed a decreasing trend. The best characteristics were obtained in the treatment of coconut fiber filler (SK) 45 phr, with a hardness value of 82 Shore $D$, tensile strength of $6.8 \mathrm{MPa}$, elongation at break with a value of $40 \%$ and tear resistance of $60 \mathrm{~N} / \mathrm{mm} 2$ and no cracking in all treatments after 48 hours of observation. The same effect was obtained by rubber ebonite characteristics using carbon black 45 phr fillers, with mechanical properties which had insignificant value with with coconut fiber filler. The best characteristics of ebonite produced met the requirements of commercial rubber ebonite.
\end{abstract}

Keywords: Ebonite rubber, natural rubber, coconut fiber, mechanical properties.

\section{PENDAHULUAN}

Karet alam merupakan komoditi perkebunan yang berperan penting di bidang perekonomian Indonesia. Karet alam sebagai pendorong ekonomi di sentra baru yang tumbuh disekitar daerah perkebunan karet, sehingga karet alam juga menjadi sumber pendapatan dan kesejahteraan masyarakat. Selain itu komoditi hasil perkebunan ini juga memberikan kontribusi terhadap sember devisa Negara. Upaya peningkatan nilai tambah, salah satunya dilakukan melalui 
peningkatan konsumsi karet alam di dalam negeri dengan dilakukan pengembangan industri barang jadi karet, diversifikasi produk, substitusi impor bahan baku karet dan perluasan lapangan kerja.

Pada kegiatan penelitian pembuatan karet ebonit ini dilakukan dengan menggunakan filler dari serat sabut kelapa. Karekteristik mekaniknya dibandingkan dengan karet ebonit yang dibuat dari bahan pengisi carbon black. Karet ebonit dibuat menggunakan campuran karet alam, karet sintetis dan sulfur dengan ditambahkan bahan pengisi dan bahan kimia lainnya. Untuk mendapatkan tekstur yang keras, penambahan sulfur merupakan unsur kimia utama dan jumlah penggunaannya mencapai 25 sampai 60 phr. Pembuatan karet ebonit dilakukan dengan waktu yang cukup lama pada proses vulkanisasinya dengan sulfur 3- - 50\%, agar didapatkan sifat fisik yang keras dan kuat (Winya, and Pittayaprasertkul, 2015). Karena sifatnya yang tahan terhadap benturan, kuat dan rigit, sehingga pada saat ini penggunaan karet ebonit diutamakan untuk membuat komponen teknik dan keperluan elektrik. Karet ebonite juga digunakan sebagai tangki penyimpanan, bejana reaksi, dan lapisan pompa (Al-Maamori dan Hamzah, 2018).

Buah kelapa mempunyai kandungan sabut dengan perkiraan sebesar $30-45 \%$ dari berat buah kelapa (Hanum, 2015). Menurut Naveen dan Raju, 2013, komposisi kimia sabut kelapa, hemiselulosa $15-28 \%$, selulosa $35-60 \%$ dan lignin $20-48 \%$, dan mengandung gabus sebesar $25 \%$ sabut. Fungsi gabus pada sabut buah kelapa untuk menggabungkan satu serat dengan serat lainnya.

Sampai saat ini pemanfaatan sabut di Sumatera Selatan belum dilakukan secara maksimal untuk meningkatkan nilai tambahnya, hal ini terlihat di perkebunan kelapa di daerah Gasing Banyuasin, sabut kelapa masih dibuang pada di daerahdaerah perkebunan.

Pada pembuatan karet ebonit, karet alam berfungsi sebagai matrik, yaitu untuk mengikat serat serta melindungi dan meneruskan gaya yang terjadi antar serat.
Sehingga serat dapat menahan gaya yang bekerja pada material komposit. Serat diharapkan dapat menentukan karakteristik karet ebonit yang meliputi kekerasan, keuletan, kekakuan dan sifatsifat mekaniknya. Diharapkan pembuatan ebonit dengan filler dari serat kelapa ini dapat menghasilkan produk yang bermanfaat dan dapat diaplikasikan.

Pada penggunaan di alam terbuka karet alam mudah mengalami kerusakan terhadap cuaca, terutama ozon serta pengusangan/aging. Walaupun demikian karet alam juga mempunyai keunggulan, diantaranya tegangan putus, kekenyalan, ketahanan kikis dan ketahanan sobek yang baik (Sadewo et al., 2016).

Penelitian pembuatan komposit karet ebonit telah dilakukan, diantaranya oleh Mulyanto (2016), melakukan penelitian pembuatan komponen otomotif penutup spion sepeda motor menggunakan komposit karet ebonit dengan penguat dari serat bambu. Penelitian menghasilkan kekuatan tarik dan izo impact yang meningkat dengan bertambahnya muatan serat bambu. Supraptiningsih et al., (2015), melakukan penelitian pembuatan karet ebonit untuk isolator panas dari karet alam dengan menggunakan berbagai variasi penambahan karet riklim, dan sulfur. Hasil penelitian kekerasan dan specific gravity sesuai standar ebonit komersil. Namun, sifat mekanik seperti perpanjangan putus dan ketahanan sobek tidak dilakukan pengamatan, sehingga belum bisa menyimpulkan karet ebonit yang dihasilkan sesuai standar karet ebonit komersil.

Penelitian ini menggunakan serat kelapa sebagai penguat karet ebonit. Tujuan penelitian untuk menentukan karakteristik terbaik dari karet ebonit yang dibuat dengan komposit karet alam dengan serat kelapa dan diharapkan dapat memenuhi standar mutu karet ebonit komersil.

\section{BAHAN DAN METODA}

\section{Bahan}

Penelitian ini menggunakan bahanbahan, antara lain : SIR 20, serat kelapa (SK), carbon black (CB), $\mathrm{ZnO}$, asam 
stearat, minyak

minarek, tetrmetiltiuram disulfide (MBTS) tetramethyl thiuram disulfide (TMTD), sulfur, butylated hydroxytoluen (BHT), dibeli dari supplier PT. Bratacho Chemical.

\section{Peralatan}

Penggunaan peralatan meliputi, Two roll dengan ukuran mill $D 18 \mathrm{~cm}$ dan L $40 \mathrm{~cm}$, untuk kapasitas $2 \mathrm{~kg}$, hot press apparatus, timbangan analitik (Mettler p1210, $1200 \mathrm{~g}$ capacity), pengujian sifat mekanik menggunakan Durometer Frank Shore D untuk pengujian kekerasan, mengacu pada ASTM D.224015 , pengujian tegangan putus, ketahanan sobek dan perpanjangan putus dilakukan dengan alat Tensometer Lloyd 2000R menurut ASTM D 412-16 dan ASTM D.624-00(2012). Parameter ketahanan ozon dievaluasi berdasarkan ASTM D.1149-07 dengan menggunakan ruang ozon. Konsentrasi ozon adalah diatur pada 50 ppm selama 48 jam, strain $20 \%$ dengan suhu pada $\pm 37,7^{\circ} \mathrm{C}$.

\section{Metoda Penelitian}

\section{Rancangan Percobaan}

Penelitian ini dilakukan percobaan perlakuan variasi penggunaan SK. Sebagai pembanding digunakan juga penelitian dengan penambahan CB. Penelitian dilakukan dalam skala laboratorium dengan formulasi karet ebonit pada Tabel 1.

Tabel 1. Formula dari karet ebonit

\begin{tabular}{lc}
\hline Formula & $\boldsymbol{P h}^{\boldsymbol{*}}$ \\
\hline Karet alam SIR 20 & 100 \\
Serat kelapa/ carbon black & $15,25,35,45,55$ \\
ZnO & 5 \\
Asam stearat & 1 \\
BHT & 2 \\
MBTS & 2 \\
TMTD & 0,5 \\
Sulfur & 45 \\
\hline
\end{tabular}

${ }^{*}$ phr $=$ part hundred rubber

\section{Tahapan Penelitian}

Pemisahan serat dari sabut kelapa.

Pemisahan serat dari sabut kelapa dengan cara, sabut kelapa direndam dengan larutan $\mathrm{NaOH} 5 \%$ selama 6 jam. Selanjutnya dicuci, dikeringkan dan dicacah hingga $3 \mathrm{~mm} \pm 0,5 \mathrm{~mm}$.

\section{Proses Pembuatan Vulkanisat Karet}

Masing-masing bahan ditimbang dalam phr (berat per seratur karet) jumlah nya disesuaikan dengan masing-masing formula kompon.

\section{Mixing (pencampuran)}

Proses pencampuran karet dan bahan kimia lainnya dilakukan dengan alat open mill (gilingan terbuka) yang terlebih dahulu dibersihkan dari kotoran.

Tahapan pembuatan kompon karet dan vulkanisasi yaitu karet SIR 20 hasil mastikasi tambahkan masing-masing bahan pengisi $S K$, dan $C B$, variasi penambahan sesuai dengan rancangan percobaan dan giling sampai homogenkan. Bahan penggiat/activator, asam stearat dan $\mathrm{ZnO}$ ditambahkan, digiling hingga homogen. Antioksidan BHT dan pelunak (softener) minarek oil ditambahkan. Accelerator MBTS dan TMTD, lanjutkan penggilingan sampai semua bahan menjadi tercampur. Selanjutnya vulkanisator (sulfur) ditambahkan ke dalam bahan dan giling sampai homogen.

Vulkanisat ditentukan ukuran ketebalannya dengan mengukur kerenggangan roll silinder pada open mill. Vulkanisat dikeluarkan dari open mill dan letakkan diatas plastik lembaran. Kompon yang akan dicetak terlebih dahulu dipotong sesuai dengan ukuran barang karet ebonit yang akan dibuat.

\section{Peubah yang Diamati}

Pada penelitian ini pengujian vulkanisat dilakukan untuk perpanjangan putus, tegangan putus, kekerasan, ketahanan sobek dan ketahanan ozon.

\section{HASIL DAN PEMBAHASAN}

Pengaruh jumlah bahan pengisi serat kelapa dan CB terhadap sifat mekanik karet ebonit disajikan pada Gambar 1-4. Ada peningkatan kekerasan karena jumlah filler dalam komposi meningkat. Hal ini disebabkan volume bahan pengisi yang ditambahkan ke dalam karet, komposit menjadi lebih kaku, karena adanya pengurangan elatisitas 
rantai karet (Hassan et al., 2012; Aguele et al., 2014).

\section{Kekerasan}

Pada Gambar 1, terlihat bahwa semakin banyak jumlah filler SK dan CB yang ditambahkan pada karet ebonit, nilai kekerasan semakin meningkat dan mencapai optimum pada jumlah pengisi 45 phr. Komposit karet yang diisi filler CB memiliki nilai kekerasan yang lebih tinggi untuk berbagai volume bahan pengisi. hal ini menggambarkan penetrasi yang lebih baik dari filler CB dalam matriks karet. Kekerasan juga merupakan faktor rapat ikatan silang, semakin banyak ikatan silang yang menghubungkan material selama vulkanisasi, semakin sulit vulkanisasi akhir. Oleh karena itu, CB membentuk ikatan silang yang lebih kuat dengan matriks karet dari pada SK.

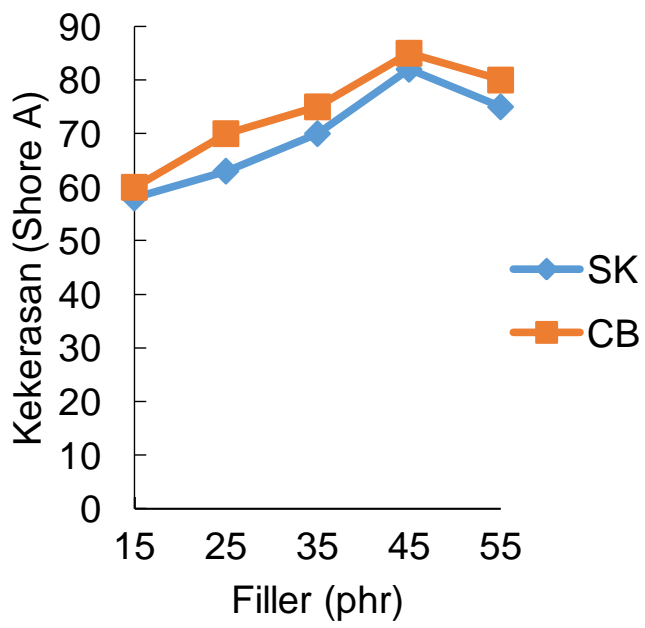

Gambar 1. Kekerasan karet ebonit

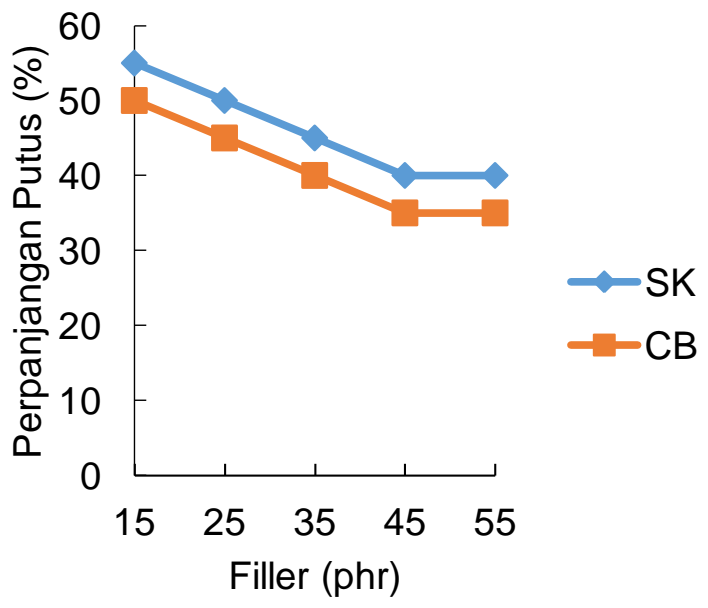

Gambar 3. Perpanjangan putus karet ebonit
Namun, nilai kekerasan karet ebonit dengan filler SK memiliki potensi sebagai bahan pengisi penguat, berdasarkan Gambar 1 yang memilik tren yang sama dengan filler komersial CB, karena nilai kekerasan tidak signifikan dengan kekerasan karet ebonit dengan filler CB. Sesuai dengan karakter karet ebonit memiliki sifat keunggulan yang kuat, rigid, dan tahan pukulan/benturan (Malomo et al., 2019). Perlakuan jumlah bahan pengisi 45 phr, menunjukkan kekerasan yang paling tinggi bila dibandingkan dengan beberapa perlakuan lainnya, yaitu sebesar 82 Shore D dan 85 Shore D. Perlakuan bahan pengisi SK 45 phr dengan kekerasan 82 Shore D, sesuai spesifikasi karet ebonit komersil dengan kisaran hardness 80 hingga 85 Shore D. (Erwin Telle GmbH supplies industrial products).

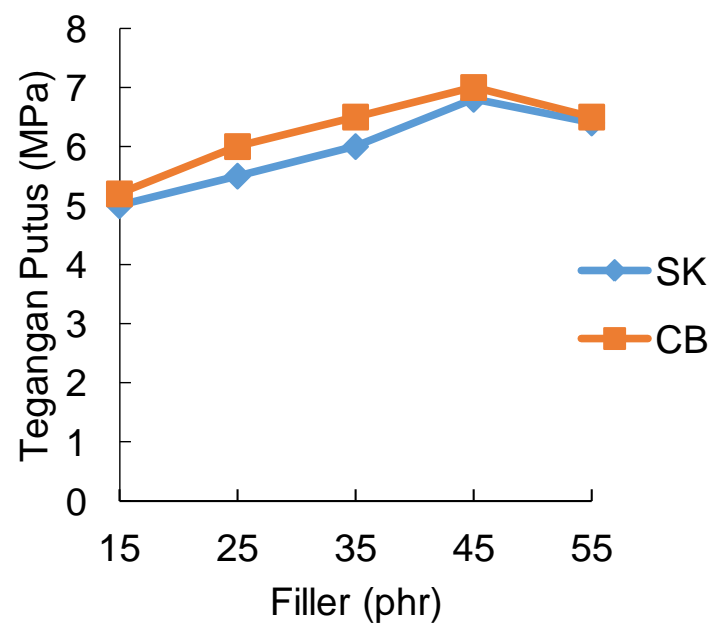

Gambar 2. Tegangan putus karet ebonite

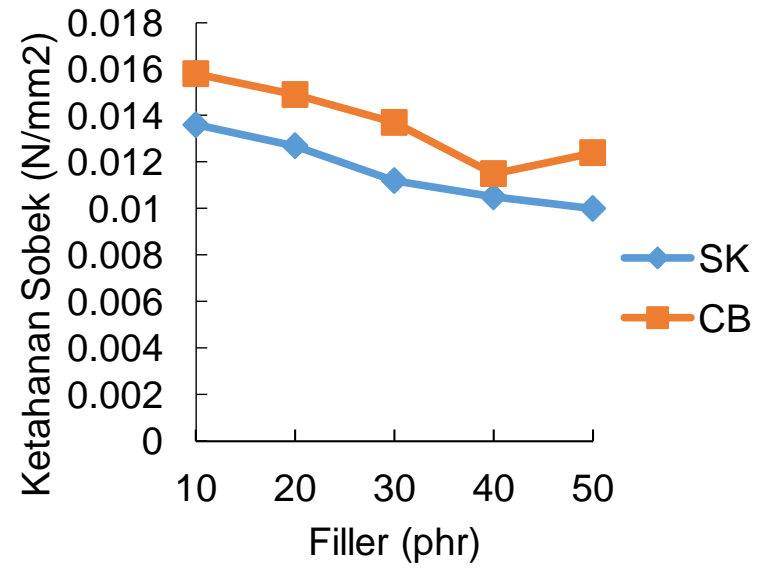

Gambar 4. Ketahanan sobek karet ebonit 


\section{Tegangan Putus}

Gambar 2 menunjukkan tegangan putus karet ebonit mengalami peningkatan dengan bertambahnya jumlah filler SK maupun $\mathrm{CB}$. Tegangan putus tertinggi diperoleh pada perlakuan bahan pengisi SK dan CB 45 phr, yaitu 6, 8 MPa dan 7 $\mathrm{MPa}$. Carbon black akan meningkatkan tegangan putus jika interaksi antara filler CB dan polimer lebih kuat. Tetapi struktur carbon black yang besar dapat meningkatkan viskositas dari kompon karet vulkanisat sehingga kemampuan carbon black untuk meningkatkan tegangan putus menjadi berkurang. Hal ini yang menyebabkan tegangan putus karet ebonit dengan jumlah filler SK dan CB 45 phr menghasilkan nilai tegangan putus yang tidak signifikan. Semakin bertambahnya jumlah filler SK dan CB akan menyebabkan semakin tinggi rapat ikatan silang yang timbul dari reaksi vulkanisasi yang terbentuk dalam jaringan molekul karet. Selain itu, peningkatan tegangan putus dikaitkan dengan interaksi pengisi dengan molekul karet yang lebih kuat karena dispersi pengisi yang dihomogenisasi (Munirah et al., 2016). Menurut Oktaviana et al., (2015), filler yang berasal dari serat alami, mengandung selulosa, yang bersifat penguat alami, mempunyai struktur rantai yang mirip dengan senyawa hidrokarbon pada minyak bumi. Pemecahan rantai panjang dalam senyawa selulosa bertujuan untuk membuat senyawasenyawa kimia dengan berat molekul yang rendah dari agregat karbon. Karbon yang terdapat dalam SK kemungkinan dapat memberikan dampak penguatan pada vulkanisatnya. Perlakuan terbaik nilai tegangan putus diperoleh pada bahan pengisi SK 40 phr, yaitu sebesar 6,8 $\mathrm{MPa}$, sesuai tegangan putus karet ebonit komersil minimal $6 \mathrm{MPa}$.

\section{Perpanjangan Putus}

Berdasarkan Gambar 3, vulkanisat yang diisi SK dan CB memiliki tren cenderung menurun dengan semakin bertambahnya jumlah bahan pengisi. Hal ini berhubungan dengan jumlah pengisi yang ditambahkan dalam matriks karet, ukuran partikel bahan pengisi dan luas dispersi. Semakin banyak pengisi SK yang ditambahkan kedalam matriks karet, vulkanisat menjadi lebih kaku dan kurang rentan terhadap elastistas vulkanisat, sehingga mengurangi nilai perpanjangan putus. Nilai perpanjangan putus adalah indikasi untuk penguatan yang lebih sedikit (Husseniyah and Mostapha, 2011; Momoh et al, 2016).

Penurunan perpanjangan putus disebabkan adanya interaksi pengisi ke matriks karet. Sehingga terjadinya pengerasan rantai polimer dan karenanya resisten untuk meregangkan, sehingga perpanjangan putus menurun (Ojinmah et al., 2017; Phrommedetch dan Pattamaprom, 2010). Selain itu, pada penelitian ini menggunakan sulfur sebanyak 45 phr, hal ini menyebabkan nilai perpanjangan putus menurun. Tidak semua SK dapat berikatan dengan molekul karet, hal ini dimungkinkan karena terjadinya aglomerisasi agregat, yaitu semakin banyak bahan pengisi ditambahkan, perpanjangan putus akan menurun. Vulkanisat karet akan mudah putus bila ditarik, hal ini disebabkan molekul karet yang sudah jenuh dengan penambahan SK.

Menurut Honggokusumo (2006), vulkanisasi karet alam dengan menggunakan sulfur dalam jumlah besar (lebih dari 30 phr) akan terbentuk ikatan silang monosulfida yang cukup banyak, yang menyebabkan vulkanisasi bersifat kaku atau kehilangan sifat fleksibilitasnya sehingga pada saat ditarik perpanjangan putusnya sangat kecil.

Nilai perpanjangan putus terkecil diperoleh pada perlakuan bahan pengisi SK dan CB 45 dan 55 phr, yaitu $40 \%$ dan $35 \%$ Untuk semua perlakuan, nilai perpanjanga putus karet ebonit sesuai dengan Perpanjangan putus karet ebonit komersil, yaitu minimal $10 \%$.

\section{Ketahanan Sobek}

Hasil pengujian untuk parameter ketahanan sobek pada karet ebonit seperti pada Gambar 4. Berdasarkan Gambar 4, semakin bertambah jumlah SK dan CB, ketahanan sobek semakin meningkat serta mencapai tingkat yang optimum untuk perlakuan bahan pengisi 
$45 \mathrm{phr}$, yaitu masing- masing $60 \mathrm{~N} / \mathrm{mm}^{2}$ dan $75 \mathrm{~N} / \mathrm{mm}^{2}$. Meningkatnya ikatan silang antara molekul karet dengan SK dan CB menyebabkan meningkatnya ketahanan sobek.

Peningkatan kerapatan ikatan silang antar molekul karet dapat disebabkan karena adanya interaksi bahan pengisi dengan molekul karet. Menurut Sugiyono dan Prasetya (2018), waktu pakai produk akan semakin lama, apa bila semakin tinggi ketahanan sobeknya. Tingginya ketahanan sobek akan menghasilkan vulkanisat yang semakin baik. Bertambah besarnya kebutuhan tenaga untuk menarik karet sampai putus, dipengaruhi oleh nilai ketahanan sobek yang semakin besar. Hal ini mengindikasikan bahwa semakin baik ketahanan sobek, bila vulkanisat karet menggunakan bahan pengisi SK.

Perlakuan pada penelitian yang memenuhi persyaratan standar mutu karet ebonit komersil (Erwin Telle $\mathrm{GmbH}$ supplies industrial products), ketahanan sobek minimal $60 \mathrm{~N} / \mathrm{mm}^{2}$, yaitu perlakuan pengisi SK 45 phr, yaitu 60 phr. Perlakuan bahan pengisi CB 25 phr hingga 55 phr, dengan kisaran nilai 60 hingga 75 phr. Pada pengisi CB nilai ketahan sobek untuk semua perlakuan memenuhi standar mutu komersil, kecuali perlakuan pengisi 15 phr, hal ini disebabkan ukuran partikel kecil, sifat, struktur dan aktivitas permukaan CB yang tinggi dibandingkan dengan ukuran partikel dan sifat lainnya dari SK. Ukuran partikel, struktrur dan aktivitas permukaan bahan, sangat mempengaruhi interaksi bahan dengan senyawa lainnya (Aguele et al, 2012; Okele et al, 2015).

\section{Ketahanan Ozon}

Karet ebonit dilakukan pengujian ketahanan ozon dengan konsentrasi ozon 50 ppm, selama periode waktu 48 jam. Hasil pengujian dilihat secara langsung dan dinyatakan dengan cracks atau no cracks (retak atau tidak retak).

Hasil pengujian untuk parameter ketahanan ozon pada karet ebonit seperti pada Tabel 2.

Hasil pengamatan semua perlakuan sampai 48 jam karet ebonit, ditunjukkan pada Tabel 2, semua perlakuan tidak mengalami keretakan. Karet ebonit tidak mengalami keretakan karena adanya pengaruh antioksidan sehingga mampu melindungi vulkanisat karet dari kerusakan yang disebabkan oleh oksigen, ozon, dan cahaya matahari.

Tabel 2. Hasil pengujian ketahanan ozon

\begin{tabular}{ccc}
\hline $\begin{array}{c}\text { Perlakuan } \\
\text { (phr) }\end{array}$ & \multicolumn{2}{c}{ Hasil Uji } \\
\cline { 2 - 3 } & SK & CB \\
\hline 15 & Tidak retak & Tidak retak \\
25 & Tidak retak & Tidak retak \\
35 & Tidak retak & Tidak retak \\
45 & Tidak retak & Tidak retak \\
55 & Tidak retak & Tidak retak \\
\hline
\end{tabular}

Selain itu, beberapa faktor antara lain diantaranya adalah penggunaan antidegradan yang mempunyai aktivitas tinggi dan sesuai dengan kebutuhan, dapat meningkatkan ketahanan vulkanisat karet terhadap ozon.

Pada penelitian ini menggunakan antioksidan jenis Butil Hidroksi Toluen (BHT) dengan jumlah sebanyak 2 phr. BHT merupakan antioksidan primer, dapat menghentikan terbentuknya reaksi berantai radikal bebas yang melepaskan hidrogen. Reaksi ozon dengan antiozonan jauh lebih cepat dari pada reaksi dengan ikatan rangkap pada permukaan molekul karet. Permukaan molekul karet dilindungi dari serangan ozon sampai permukaan antiozonan habis bereaksi dengan ozon dipermukaan karet, difusi antiozonan dari bagian dalam ke permukaan terus mengisi konsentrasi permukaan antiozonan untuk memberikan perlindungan terus menerus terhadap ozon.

Bahan pengisi memberikan peranan yang cukup besar terhadap ketahanan karet ebonit terhadap ozon. Interaksi antara filler dengan molekul pada karet akan membentuk ikatan silang yang kuat dengan adanya sulfur sehingga komposit karet akan menjadi lebih kuat. Semakin kuat ikatan yang terbentuk, semakin rendah kerentanan terhadapa ozon. Selain itu, senyawa karet yang memiliki rantai utama hidrokarbon memiliki ketahanan ozon, ketahanan terhadap panas dan oksidasi yang sangat baik (Ooi et al., 2014; Ning et al., 2015). 


\section{KESIMPULAN DAN SARAN}

\section{Kesimpulan}

Serat kelapa memiliki potensi sebagai bahan pengisi penguat alami. Hasil penelitian menunjukkan sifat mekanik karet ebonit dipengaruhi oleh filler. Serat kelapa dan carbon black yang digunakan sebagai filler menunjukan kekerasan, tegangan putus dan ketahanan sobek yang lebih tinggi. Namun, perpanjangan putus lebih rendah dari pada bahan pengisi serat kelapa. Karakteristik mekanik vulkanisat terbaik diperoleh pada perlakuan bahan pengisi serat kelapa (SK) 45 phr, dengan nilai kekerasan 82 Shore D, tegangan putus sebesar 6,8 $\mathrm{MPa}$, perpanjangan putus dengan nilai $40 \%$ dan ketahanan sobek $60 \mathrm{~N} / \mathrm{mm}^{2}$ dan tidak ada retak (no crack) pada semua perlakuan setelah 48 jam pengamatan. Karakteristik karet ebonit menggunakan bahan pengisi carbon black 45 phr, dengan karakterisitk mekanik yang memiliki nilai tidak signifikan dengan karet ebonit dengan filler serat kelapa. Karet ebonit dengan filler serat kelapa dapat menjadi sumber bahan baku yang berguna untuk produk hard rubber.

\section{Saran}

Perlu dilakukan penelitian lanjutan untuk pemgembangan formula karet ebonit menggunakan serat yang lainnya seperti serat kelapa sawit.

\section{UCAPAN TERIMA KASIH}

Ucapan terima kasih kami sampaikan kepada Bapak Bambang Sugiyono, Ibu Mimi Kurnia Yusya dan Bapak Aidil atas bantuannya pada praktek lapangan, dan pengujian di laboratorium hingga selesainya penelitian ini.

\section{DAFTAR PUSTAKA}

Aguele, F.O., Madufor, C.I. and Adekunle, K.F. (2014). Comparative Study of Physical Properties of Polymer Composites Reinforced With Uncarbonised And Carbonised Coir. Open Journal of Polymer Chemistry. 4: 73-82.

Al-Maamori. M.H and Hamzah, A.F. (2018). Effect of sulfur and Nano-carbonblackon the mechanical properties of hard rubber. Journal of University of Babylon, Engineering Sciences. 26(2): 127-134.

Hanum, M.S. (2015). Eksplorasi Limbah Sabut Kelapa. e-Proceeding of Art \& Design. 2(2) : 930-938. Agustus 2015.

Hassan, S., Ogherevwet, E.J and Aigbodion, V. (2012). Potential of Maize Stalk Ash as Reinforcements for Polyester Composites, Journal of Minerals and Materials Characterization and Engineering. 11(4): 543 - 557.

Honggokusumo, S. (2006). Kimia dan Teknologi Vulkanisasi. Makalah Teknologi Barang Jadi Karet BPPT. Bogor.

Husseniyah, S. and Mostapha M. (2011). The Effect of Filler Content on Properties of Coconut Shell Filled Polyester Composites, Malaysian Polymer Journal. 6(1): 87-97.

Malomo, D., Obinna, Edeh, E., Okolo, P., Felix, C., Ibeh and Adewuyi, S.O. (2019). Preparation and Properties of NR Based Ebonite Rubber Suitable for Use as Engineering Material. Evolution in Polymer Technology Journal 2(1):1-5.

Momoh, F.P, Mamza, P.A.P, Gimba, C.E and Nkeonye, P. (2011). Morphological Trends of Modified Coconut Fibre in Natural Rubber Reinforcement. Journal of Emerging Trends in Engineering and Applied Sciences. 7(4): 167- 172.

Mulyanto, A. (2016). Pengembangan Komposit Dari Karet Ebonit dengan Penguat Serat Bambu Untuk Komponen Otomotif Penutup Spion Sepeda Motor. Skripsi Universitas Muhammadiyah Surakarta.

Munirah, N.R, Noriman, N.Z, Salihin, M.Z, Sam, S.T. Mustafa AL Bakri, A.m, Fatin, M.H, Rosniza, H. (2016). The Effects on Cure Characteristics, PhysicoMechanical Properties and Morphology of Bamboo Activated Carbon Filled Styrene Butadiene Rubber (SBR) Vulcanizates. Key Engineering Materials 673: 131-140.

Ning, N.Y, Zheng, Z.P, Zhang, L.Q, Tian, M. (2015). An Excellent Ozone-Resistant Polymethylvinylsiloxane Coating on Natural Rubber By Thiol-Ene Click Chemistry. eXPRESS Polymer Letters 9(6): 490-495.

Naveen, P.N.E., and Rahu, T. D. (2013). Evaluation of Mechanical Properties of Coconut Coir Fiber Reinforced Polymer Matrix Composites. Journal of Nano Research. 24: 34-45 
Ojinmah N, Uchechukwu TO, Ezeh VO dan Ogbobe O. (2017). Studies on the Effect of Rice Husk Semi-Nano Filler on the Mechanical Properties of Epoxidized Natural Rubber Composite. European Journal of Advances in Engineering and Technology. 4 (3): 164-171.

Okele, I.A., Mohammed, F., Agho, B.O., Marut, A.J and Jekada, J.Z. (2015). Experimental Study on Particle Size and Filler Loading Reinforcement of Sugar Canebaggase on Natural Rubber Compound. Research and Review in Polymer. 6(4): 155-160.

Oktaviana, R., Sitorus, B dan Malino, M.B. (2015). Pengaruh 3Aminopropyltriethoxysilane Terhadap Sifat dan Morfologi Komposit Karet Alam-Selulosa Tandan Kosong Kelapa Sawit. JKK, 4(4) : 94-100.

Ooi, Z.X., Ismail, H and Bakar, A.A. (2014). Study on The Ageing Characteristics of Oil Palm Ash Reinforcednatural Rubber Composites by Introducing A Liquid Epoxidized. Polymer Testing. 37: 156-162

Phrommedetch, S and Pattamaprom, C. 2010. Compatibility Improvement of Rice Husk and Bagasse Ashes with Natural Rubber by Molten-State Maleation. Europe Journal Science Research. 43(3): 411-416.

Sadewa, A.B., Joko. S dan Bambang, W.F. (2016). Pengembangan Komposit dari Karet Ebonit dengan Penguat Serat Serabut Kelapa untuk Komponen Otomotif Penutup Spion Sepeda Motor. Skripsi Teknik Mesin Fakultas Teknik Universitas Muhammadiyah Surakarta.

Sugiyono, B dan Prasetya, HA. (2018). Pengaruh Arang Aktif Bambu Terhadap Karakteristik Pematangan dan Sifat Mekanik Karet Peredam Goncangan Kendaraan Bermotor. Jurnal Dinamika Penelitian Industri. 29(2): 91 - 98.

Supraptiningsih, Herminiwati, Yuniari, A., Sugihartono dan Sholeh, M. (2015). Pembuatan Karet Ebonit Pada Berbagai Variasi Karet Alam, Karet Riklim, dan Sulfur untuk Isolator Panas. Jurnal Teknologi Agro-Industri. 2(1): 1 - 9.

Winya, N and Pittayaprasertkul, N. (2015). SiO2Reinforcement of Mechanical Properties for Ebonite from Natural Rubber. International Journal of Chemical Engineering and Applications. 6(3): 169-172 